\title{
When a Facility Dog Became My Own Personal Therapist
}

\author{
Morgan Yordy, DNP, ACNS-BC, RN-BC \\ Auburn University School of Nursing
}

Submitted 24 April 2020: accepted 1 June 2020

Keywords: facility dog, self-care, faculty-staff wellness

College can be a time of growth, fun, and excitement, but also a time for enhanced stress and anxiety for students. Literature supports the heightened levels of anxiety experienced by present day college students compared to previous generations (Binfet, Passmore, Cebry, Struik, \&McKay, 2017; Ward-Griffin, Klaiber, Collins, Owes, Coren, \& Chen, 2018; Wood, Ohlsen, Thompson, Hulin, \& Knowles, 2018). In addition, student stress does not return to the precollege level during their tenure at school (Ward-Griffin et al., 2018). The American College Health Association (ACHA) reported over half the students seeking counseling services were due to anxiety (ACHA, 2020). Yet, reports exist that state there is not enough counseling staff or resources to meet the needs of all college students (Stewart, Dispenza, Parker, Change, \& Cunnien, 2014).

Animal assisted therapy (AAT) programs have been gaining in popularity across college campuses. A recent study found around $62 \%$ of higher education institutions have AAT programs with many of them utilizing only canines as the therapy animal of choice (Haggerty \& Mueller, 2017). Evidence supports these types of programs across campus. Binfet et al. (2017) studied the benefit of frequent therapy canine sessions utilizing up to 17 canine-handler teams during their program, Building Academic Retention through K9s (B.A.R.K). The 1,960 participants of the programs representing over $25 \%$ of the undergraduate population reduced their stress to a significant degree. Another study of 246 students conducted by Ward-Griffin et al. (2018) discovered therapy sessions consisting of 7-12 canine handler teams reduced stress and increased happiness in those that participated. In addition, these feelings translated hours after the visit. Not only are scheduled sessions beneficial, but drop-in visits twice a month have also been shown to reduce stress. A pilot study conducted by Stewart et al. (2014) found a decrease in reported stress levels for students living in a residence hall.

Biometric data support the use of animals in colleges to combat some of the stress and anxiety students experience. Jarolmen \& Patel (2018) studied exam anxiety and blood pressure changes. The experimental group spent 15-minutes with the therapy animals prior to their examination. Those in the experimental group had a decrease in blood pressure on the day of the exam. Another study conducted by Wood et al. (2018) reported similar findings from 127 students. Students completed a trait anxiety scale and a state anxiety scale (state focuses on a response to a situation), and blood pressure pre and post-therapy dog intervention (during the post-therapy the student did not complete an addition trait anxiety scale as this scale is relatively stable). The finding suggested spending time with canines does decrease perceived stress and blood pressure, especially in female participants.

There are countless studies linking the benefits of AAT programs on college campuses for students, but there is a gap in the literature among the benefits to faculty and staff. A quick search yielded no returns regarding faculty and staff perceptions of AAT on a college campus. Do faculty and staff report the same stress and anxiety reduction in 
the presence of the therapy canine as their students' experience? Are there benefits of canine therapy to faculty and staff? One case study does shed light on the benefit of a therapy canine for a faculty member.

A faculty member at a school of nursing in the southeastern United States is part of a university dog handler team. The team is composed of a handler with about 10 years' experience in AAT and a 3-year-old, certified, and trained Goldendoodle named "Daisy." Although housed at the school of nursing, the team is part of the university and provides services across campus and the community. Daisy has touch countless lives, but mid-November 2019 was her most important job yet. During this time, her handler experienced extreme stress and anxiety over the unexpected death of her husband, the father of their three very young children. Over the course of a few weeks, Daisy and the family pet Clarabelle, who is not part of the university AAT program but part of a pet ministry at church, sat with their handler as she cried. They were a quiet presence when hard decisions had to be made. They also provided comfort to the children as they talked about their dad with tears rolling down their cheeks. These two therapy animals became this family's personal therapist. Their devotion to their handler and family lessened the unimaginable stress and anxiety experienced due to this unexpected loss.

As months went by, Daisy returned to her role at the university, with modifications; she spent a significant amount of quiet time with her handler during the first few weeks of the Spring semester 2020. Having Daisy lessened the anxiety at work as her handler returned to a "new normal." But just as the semester began rolling, the Pandemic called COVID-19 struck, and the university transitioned to remote instruction. Once again as heightened levels of anxiety and stress emerged, Daisy and Clarabelle were there to lessen the blow.

As this faculty began to navigate remote instruction, Daisy's returned back to her job at the university. The team chose to build on their relationship and take what was learned during the initial grief experienced during the fall and apply it to the students, fellow faculty, and staff during the pandemic. Students, faculty, and staff need to feel supported and unconditional love. Daisy hosted video conferences with students, faculty, staff, and their pets to discuss the positives of social distancing during this time. Daisy posted messages on social media about steps to take with your own pet to help lessen the stress, anxiety, and loneliness experienced during the pandemic. Although we could not experience the physical touch, Daisy and all the pets brought a sense of joy during these unprecedented times. Many that attended the remote therapy sessions found them to be fun, enjoyable, and helpful and even suggested they continue when we return to the physical campus.

So, are there benefits of canine therapy for faculty and staff at a college or university? I would have to say yes. Daisy became my family's personal therapist. I see now not only the impact she has on myself and my children, but also the impact she has on those encountered within the university setting. This is just a one case example of the benefits of AAT, but it could shed light on the importance of taking care of our faculty and staff during periods of stress and anxiety. Animal assisted therapy could be utilized in varying ways to build healthy academic communities. 


\section{REFERENCES}

American College Health Association (2020). Fall 2019 Reference Group Data Report. National College Health Assessment. Retrieved November 2, 2020 from https://www.acha.org/documents/ncha/NCHAIII_FALL_2019_REFERENCE_GROUP_DATA_REPORT.pdf

Binfet, J.T., Passmore, H.A., Cebry, A., Struik, K. McKay, C. (2018). Reducing university students’ stress through a drop-in canine-therapy program. Journal of Mental Health, 27(3), 197-204. https://doi.org/10.1080/09638237.2017.1417551

Haggerty, J. M., \& Mueller, M. K. (2017). Animal-assisted stress reduction programs in higher education. Innovative Higher Education, 42(5-6), 379-389. https://doi.org/10.1007/s10755-017-9392-0

Jarolmen, J. \& Patel, G. (2018). The effects of animal-assisted activities on college students before and after a final exam. Journal of Creativity in Mental Health, 13(3), 264-274. https://doi.org/10.1080/15401383.2018.1425941

Stewart, L.A., Dispenza, F., Parker, L., Chang, C.Y. \& Cunnien, T. (2014). A pilot study assessing the effectiveness of an animal-assisted outreach program. Journal of Creativity in Mental Health, 9, 332-345. https://doi.org/10.1080/15401383.2014.892862

Ward-Griffin, E., Klaiber, P., Collins, H.K., Owens, R.L., Coren, S. \& Chen, F.S. (2018). Petting away pre-exam stress: The effect of therapy dog sessions on student well-being. Stress and Health, 34, 468-473. https://doi.org/10.1002/smi.2804

Wood, E., Ohlsen, S., Thompson, J., Hulin, J., \& Knowles, L. (2018). The feasibility of brief dog-assisted therapy on university students stress levels: The PAwS study. Journal of Mental Health, 27(3), 263-268. https://doi.org/10.1080/09638237.2017.1385737

Address author correspondence to:

Morgan Yordy, DNP, ACNS-BC, RN-BC

Auburn University School of Nursing

bmy0004@auburn.edu 